\title{
CONTRACEPTION IN WOMEN OVER FORTY
}

\author{
F. E. RIPHAGEN*, J. A. FORTNEY† AND S. KOELB*
}

* International Health Foundation, Geneva, Switzerland, and Brussels, Belgium, and $\dagger$ Family Health International, Research Triangle Park, NC, USA

\begin{abstract}
Summary. Contraception in women over the age of 40 has received little attention, and accurate data are not readily available. This paper compares data from surveys from the United States and five major countries in Western Europe. Consideration is given to the possible effect on these women of the threat of reduced availability of suitable contraceptive methods as a result of current developments within society at large. This is of particular importance as it appears that, especially in Western Europe, contraception is underutilized in this age group. The benefits and risks of various methods of contraception are discussed. Use of the pill by older women remains controversial. Misconceptions about pill use and the IUD seem to be widespread among women of all ages.
\end{abstract}

\section{Introduction}

Little is known about contraception in women over the age of 40. Population surveys usually stop at the age of 44 or 45 , ignoring the 5 years (on average) of remaining reproductive life. It is remarkably difficult to obtain information on the methods of contraception used by older women, and nearly impossible to find out why a particular method was chosen (WHO, 1981). That scant attention has been paid to this age group can also be seen in the lack of an age-specific range of contraceptive methods for women over 40 .

In the United States, no national contraceptive prevalence survey since the 1965 National Survey of Family Growth has included women aged 45 or over, although the Cancer and Steroid Hormone Study carried out by the US Centers for Disease Control in 1982 (CDC, 1983) provided some information about the fecundity status of US women over 44. In fact, much of the information that is at present available comes from data collected for other purposes.

The lack of information is particularly striking because of the attitudes and behaviour of this age group. Women over 40 are today showing a greater interest in contraception; they are the women whose attitudes were influenced by the sexual revolution of the 1960s. They do not fit the popular image of the middle-aged mother who has fulfilled her role of bearing children and no longer takes an interest in sex. Moreover, there is evidence to indicate that an increasing number of couples are intentionally choosing to have their children at a later stage in their lives, as the result of changing social and economic trends in several Western countries (Francis, 1985). 
Yet, even as planning of births increasingly extends into older age ranges, the availability of suitable contraception is under growing threat as the result of the cost of litigation following mishaps with some contraceptive methods, the negative publicity being given to some methods, and the consequent decreasing enthusiasm for research and development within the industry.

\section{Data and methods}

Data used for Western Europe are taken from the five-country survey of 8180 women conducted by the International Health Foundation. The survey, carried out in 1984 and 1985, covered women between 15 and 45 years of age in Italy, France, Great Britain, Spain and the Federal Republic of Germany, and the results have been published separately for each country (Riphagen, van der Vurst \& Lehert, 1984, 1985a,b, 1986a,b). In this paper, only data on women between 41 and 45 are used, unless stated otherwise. In these European countries, women of 41-45 years of age represent, on average, $15 \%$ of all women aged $15-45$. In the International Health Foundation data they numbered $961,13 \%$ of the total.

The samples used - which, with the exception of Spain, were not purely randomcompared in age, marital status and level of education to the national population of each country were found to be representative (Riphagen et al. 1984, 1985a,b, 1986a,b). Contraceptive use rates for the total populations were compatible with those of countries for which recent, reliable data are available (World Fertility Survey, 1981, 1982; OPCS, 1985; INE, 1986).

In view of the relatively small size of the European subsamples, the methods used, and the fact that the studies were not aimed at this age group, the data should be considered only as indicators of attitudes and opinions, which are nonetheless interesting in their implications.

For the United States, the data came from women between the ages of 40 and 54 , although in several cases statistics are presented for women between 40 and 44. Data were not derived from a sample specifically obtained for this study but were taken from previously published data, particularly the 1982 National Survey of Family Growth (NSFG) (Pratt et al., 1984) and the 1982 Market Survey, a nationally representative survey carried out by a large pharmaceutical company (Forrest \& Henshaw, 1983).

\section{Population at risk}

In 1982 there were approximately 13 million American women aged 40-49, most of them sexually active, and many still able to conceive (Pratt et al., 1984). Of those women who are exposed to the risk of pregnancy (i.e. sexually active and neither sterile nor pregnant), $20 \%$ are not using any method of contraception (Table 1 ). This is a higher percentage than in any other age group, including teenagers (Forrest \& Henshaw, 1983, Table 5 recalculated).

Between $20 \%$ and $30 \%$ of women aged 4044 have had a hysterectomy; the exact percentage depends on the data source (Table 2). The prevalence of hysterectomy varies by region, being lowest in the north-east and highest in the south (Walker \& 
Table 1. Percentage of US women exposed to the risk of pregnancy who use no method of contraception, by age (NSFG, 1982)

\begin{tabular}{cc}
\hline Age (years) & \% using no method \\
\hline $15-19$ & 18 \\
$20-24$ & 12 \\
$25-29$ & 8 \\
$30-34$ & 9 \\
$35-39$ & 16 \\
$40-44$ & 21 \\
\hline
\end{tabular}

Source: Pratt et al. (1984).

Jick, 1979) (Table 3). Natural menopause has occurred in about $3 \%$ of women aged $40-44,11 \%$ of those aged $45-49$, and $43 \%$ of those aged $50-54$. This is in addition to those with a surgical menopause (Table 4). Thus, almost $30 \%$ of women aged $50-54$ have not yet passed menopause.

Approximately $10 \%$ of women in the $40-44$ age group are not at risk of unintended pregnancy because they are either pregnant, post-partum, seeking pregnancy or not sexually active. Corresponding figures are not available for the 45-54 age group. Figures for women in the five European countries under consideration (Table 5) show that the percentage of women between the ages of 41 and 45 who are not at risk because they are either pregnant or seeking pregnancy ranged from $0 \%$ (Federal Republic of Germany) to 5\% (Italy). The corresponding figure is about $1.5 \%$ for American women between 40 and 44 years of age (Table 4).

Sexually non-active women in the European countries ranged from $1 \%$ (Italy) to $21 \%$ (Spain), but this figure is somewhat dubious; the number of women who are not sexually active is quite low, with the exception of Spain.

This is not an isolated finding, for, though few data are available for Spain, all

Table 2. Prevalence of hysterectomy in US women aged $40-54$

\begin{tabular}{lllll}
\hline & & \multicolumn{4}{c}{ Age (years) } \\
\cline { 3 - 5 } \multicolumn{1}{c}{ Study } & Year & $40-44$ & $45-49$ & $50-54$ \\
\hline NSFG* $^{*}$ & 1982 & $21 \cdot 8$ & & \\
CASH (controls) $\dagger$ & $1981-2$ & $20 \cdot 1$ & $30 \cdot 9$ & $28 \cdot 3$ \\
CPHA & 1975 & $28 \cdot 4$ & $31 \cdot 5$ & $30 \cdot 8$ \\
Upstate NY§ & 1982 & $15 \cdot 1$ & $24 \cdot 3$ & 25.9 \\
\hline
\end{tabular}

Sources: * NCHS special computer run; $†$ Cancer and Steroid Hormones, FHI special computer run; $\ddagger$ Commission on Professional and Hospital Activities, Walter \& Jick (1979); $\S$ Howe (1984), Nolan et al. (1982). 
Table 3. Prevalence (\%) of natural and surgical menopause in the United States, 1980-82

\begin{tabular}{|c|c|c|c|c|c|}
\hline \multirow[b]{2}{*}{ Menopause } & \multirow{2}{*}{$\begin{array}{c}\text { NSFG } \\
1982 \\
40-44\end{array}$} & \multirow{2}{*}{$\begin{array}{c}\text { Market survey } \\
1982 \\
40-44\end{array}$} & \multicolumn{3}{|c|}{$\begin{array}{l}\text { Controls for CASH study } \\
\qquad 1980-82\end{array}$} \\
\hline & & & $40-44$ & $45-49$ & $50-54$ \\
\hline Natural & $3 \cdot 0$ & & $2 \cdot 1$ & $11 \cdot 3$ & $43 \cdot 0$ \\
\hline Surgical & $21 \cdot 8$ & & $20 \cdot 1$ & $30 \cdot 9$ & $28 \cdot 3$ \\
\hline Total & $24 \cdot 8$ & $18 \cdot 0$ & $22 \cdot 2$ & $42 \cdot 2$ & $71 \cdot 3$ \\
\hline$N$ & 794 & & 956 & 1503 & 1876 \\
\hline
\end{tabular}

Sources: Special computer runs from NSFG and CASH.

other age groups in Spain also show a low percentage of sexual activity. Unfortunately, the Encuesta de Fecundidad 1985 did not include questions on sexual activity, thus rendering determination of the exposed population more difficult (INE, 1986). In the United States the percentage of those not sexually active is about $8 \%$ for women between 40 and 44 years old (Table 4).

The percentage of those who stated they were infertile for reasons other than contraceptive sterilization of one of the partners ranged from $7 \%$ (Italy) to $16 \%$ (Federal Republic of Germany and France). The percentage for Italy, however, seems to be low considering that early hysterectomies, estimated by van Keep,

Table 4. Percentage distribution of US women aged $40-54$ not at risk of unintended pregnancy, by reason, $1980-82$

\begin{tabular}{|c|c|c|c|c|c|}
\hline \multirow[b]{2}{*}{ Reason } & \multirow{2}{*}{$\begin{array}{c}\text { Market survey } \\
40-44\end{array}$} & \multirow{2}{*}{$\begin{array}{l}\text { NSFG } \\
40-44\end{array}$} & \multicolumn{3}{|c|}{ Controls for CASH } \\
\hline & & & $40-44$ & $45-49$ & $50-54$ \\
\hline \multicolumn{6}{|c|}{ Contraceptive sterilization } \\
\hline Male & 17.5 & $13 \cdot 3$ & & & \\
\hline Female & $23 \cdot 4$ & $26 \cdot 4$ & & & \\
\hline Menopausal & $18 \cdot 0$ & & & & \\
\hline Natural & & 3.0 & $2 \cdot 1$ & $11 \cdot 3$ & $43 \cdot 0$ \\
\hline Surgical & & $21 \cdot 8$ & $20 \cdot 1$ & $30 \cdot 9$ & $28 \cdot 3$ \\
\hline Pregnant & 0.5 & $0 \cdot 1$ & $0 \cdot 3$ & $0 \cdot 0$ & $0 \cdot 0$ \\
\hline Post-partum & & $0 \cdot 2$ & & & \\
\hline Seeking pregnancy & $1 \cdot 0$ & $1 \cdot 4$ & & & \\
\hline Not sexually active & $7 \cdot 0$ & 8.6 & & & \\
\hline Total not at risk & $74 \cdot 2^{*}$ & $74 \cdot 8$ & & & \\
\hline Total at risk & $25 \cdot 8$ & $25 \cdot 2$ & & & \\
\hline$N$ & 1102 & 794 & 956 & 1503 & 1876 \\
\hline
\end{tabular}

* Includes $6.8 \%$ 'infertile' and rounding errors.

Sources: as Table 3. 
Table 5. Fertility position (\%) for women aged $41-45$ in five Western European countries

\begin{tabular}{lrrrrc}
\hline & Italy & France & Great Britain & Spain & West Germany \\
\hline Postpone pregnancy & 13 & 14 & 5 & 11 & 13 \\
No (more) children & 74 & 63 & 81 & 52 & 68 \\
Pregnant (or trying) & 5 & 2 & 1 & 2 & 0 \\
Infertile* & 7 & 16 & 11 & 14 & 16 \\
Not sexually active & 1 & 5 & 2 & 21 & 3 \\
\hline
\end{tabular}

* Excluding contraceptive sterilization.

Source: Riphagen et al. $(1985,1986)$.

Wildermeersch \& Lehert (1983) at $4 \cdot 1 \%$ for this age group in these countries, are included.

Thus, in the United States nearly $70 \%$ of women in the $40-44$ age group and perhaps $30 \%$ of those aged $45-54$ are still in need of contraception. The European figures for the $41-45$ age group are higher, ranging from $63 \%$ (Spain) to $87 \%$ (Italy) (Table 5).

In the absence of exact data, estimates regarding the decline of fecundity with age in modern populations (i.e. using contraception) vary from $23-40 \%$ natural infertility at age 40 up to $80 \%$ natural infertility at age 45 (Bongaarts, 1982; Gray, 1979). In the European data, the percentage of women who claimed to be infertile is, by any standard, lower than these estimates. This discrepancy reflects the difference between projections based on retrospectively determined, age-specific infertility rates applying to whole populations, and the reality of the individual woman whose age is approximately 40 at present.

There is evidently no way for the individual woman to know with certainty that she is no longer fecund on the basis of age alone. Therefore, except for those who have had a hysterectomy or been sterilized, women must regard themselves as exposed to the risk of pregnancy.

\section{Pregnancy}

Although pregnancy is not very common in women over 40 , a fair percentage of the women questioned in the five-country European survey did not exclude the possibility of another pregnancy, though they expressed the desire to 'postpone another pregnancy' (Table 5). This seems to indicate that childbearing at a more advanced age is not considered out of the question, with the implication that reversible methods of contraception are certainly needed by women over 40 .

However, a pregnancy can be particularly devastating to an older woman. A woman over 40 will often already have grown children, a pregnancy may prove emotionally unsettling, and the risk of birth defects if she carries the pregnancy to term is much greater than at a younger age.

Furthermore, maternal mortality and morbidity are high for women in their 40 s. American data show that although there were only 20 such deaths in $1979(40-44,15$; 
Table 6. Mean interval (months) since last live birth for US women aged 40-49, 1980

\begin{tabular}{lrc}
\hline Birth progression & $40-44$ & $45-49$ \\
\hline First to second & 105 & 130 \\
Second to third & 125 & 159 \\
$3-4$ & 118 & 164 \\
$4-5$ & 109 & 149 \\
$5-6$ & 95 & 127 \\
$6-7$ & 82 & 124 \\
$7-8+$ & 57 & 77 \\
\hline
\end{tabular}

Source: Vital statistics of the United States, 1980, Vol. 1, Natality. USDHHS.

$45-49,5)$ of women 40 and older, the maternal mortality ratios in women aged $40-44$ and 45-49 (NCHS, 1984b) were respectively eight and fifty times those in women in their $20 \mathrm{~s}$.

\section{Births}

There is evidence that the mean age at birth of last child is about 40 (Gray, 1979; Jansen, 1984). In the US in 1979, women of $40-44$ had 24,461 births and 18,680 abortions. Of the births, 1904 were first births, a birth rate of 3.9 per 1000 women aged 40 -44 (Ventura, 1982). Most of these births follow a long birth interval: $56 \%$ of births to women aged $40-44$, and $67 \%$ of those to women aged $45-49$, follow a birth interval of more than 6 years (NCHS, 1984a). The lower the birth order, the longer the interval (Table 6).

\section{Contraceptive use}

Table 7 shows contraceptive use for women aged 41-45 in the five-country survey of Western Europe, compared with the wider, 15-45 age group. Figures for contraceptive use by American women aged 40-44 are given in Table 8; sterilization figures are contained in Table 9.

\section{Rhythm and withdrawal}

The use of no method or of rhythm or withdrawal is higher among older women (41-55) than among all women (15-45) (Table 7$)$ in Italy ( $84 \%$ and $56 \%$, respectively), France (46\% and $36 \%$ ) and Spain (52\% and $42 \%)$. The NSFG study of American women aged 40-44 does not give separate figures for no method or withdrawal, but for use of the rhythm method, or some variation thereof, the figure quoted is $12 \%$ (Table 8). The NSFG figure is comparable to those presented for Italy, France and Spain; other studies show a smaller percentage. The rates for Great Britain are $13 \%$ for women aged $41-45(14 \%$ for those $15-45)$ and $25 \%(43 \%)$ in West Germany. It 
Table 7. Contraceptive method use (\%) by exposed women, by age, in five Western European countries

\begin{tabular}{lrrrcr}
\hline Method & Italy & Spain & France & Great Britain & West Germany \\
\hline Age 41-45 & & & & & \\
No method & 41 & 31 & 16 & 7 & 13 \\
Rhythm & 14 & 10 & 13 & 0 & 4 \\
Withdrawal & 29 & 11 & 17 & 6 & 13 \\
Barrier methods & 12 & 23 & 9 & 23 & 7 \\
IUD & 4 & 14 & 23 & 7 & 19 \\
Pill & 0 & 8 & 10 & 3 & 36 \\
Sterilization & 0 & 3 & 12 & 54 & \\
Age 15-45 & & & & & 19 \\
No method & 30 & 26 & 24 & 10 & 14 \\
Rhythm & 12 & 7 & 6 & 1 & 7 \\
Withdrawal & 14 & 9 & 6 & 3 & 10 \\
Barrier methods & 23 & 23 & 9 & 17 & 73 \\
IUD & 15 & 13 & 19 & 8 & 38 \\
Pill & 6 & 19 & 31 & 38 & \\
Sterilization & $(1)$ & 3 & 5 & 23 & \\
\hline
\end{tabular}

Source: Riphagen et al. (1985, 1986).

Table 8. Reversible contraceptive methods used by US women (\%) aged $40-55,1982$ and 1984

\begin{tabular}{lcccc}
\hline & & & \multicolumn{2}{c}{ California Medicaid $\S$} \\
& NSFG $\dagger$ & Market Survey $\ddagger$ & \multicolumn{2}{c}{1984} \\
\cline { 4 - 5 } & 1982 & 1982 & $40-44$ & $45-55$ \\
\hline Pill & $40-44$ & $40-44$ & $6 \cdot 2$ & $11 \cdot 4$ \\
IUD & $3 \cdot 4$ & $15 \cdot 6$ & $40 \cdot 4$ & $31 \cdot 3$ \\
Diaphragm & $19 \cdot 4$ & $12 \cdot 5$ & $12 \cdot 6$ & $9 \cdot 5$ \\
Condom & $12 \cdot 9$ & $9 \cdot 4$ & $38 \cdot 2$ & $43 \cdot 8$ \\
Rhythm & $34 \cdot 8$ & $34 \cdot 4$ & $2 \cdot 6$ & $4 \cdot 0$ \\
Other* & $12 \cdot 3$ & $6 \cdot 3$ & & $100 \cdot 0$ \\
Total & $16 \cdot 9$ & $21 \cdot 9$ & $100 \cdot 0$ & 1692 \\
$N$ & $100 \cdot 0$ & $100 \cdot 0$ & 3412 & \\
\hline
\end{tabular}

* Market Survey: 15.6 spermicides, 6.3 withdrawal; NSFG: not specified. Sources: † Pratt et al. (1984); $\ddagger$ Forrest \& Henshaw (1983); $\S$ Aved (1985). 
Table 9. Prevalence (\%) of surgical contraception among

US couples, wife aged $40-44,1982$

\begin{tabular}{lcc}
\hline & NSFG* $^{*}$ & Market Survey $\dagger$ \\
\hline Woman sterilized & $26 \cdot 4$ & $23 \cdot 4$ \\
Man sterilized & $13 \cdot 3$ & $17 \cdot 5$ \\
Total & $39 \cdot 7$ & $40 \cdot 9$ \\
$N$ & 7969 & 10,000 \\
\hline
\end{tabular}

Sources: * Special computer run; † Forrest \& Henshaw (1983).

appears that older German women practise the 'safest' contraceptive behaviour of those surveyed.

The figures are not entirely reassuring since the increase in menstrual irregularities as women approach the menopause makes the rhythm method difficult to use. Despite the fact that decreased coital frequency and fecundity in older women may make rhythm more acceptable, women over 40 are unlikely, on the whole, to be using this method unless they have been successful with it before. And, on account of the high incidence of maternal morbidity and birth defects in this age group, less reliable methods cannot be recommended for women unwilling to consider abortion as a back-up measure.

\section{Sterilization}

The contrast between use of sterilization, a no-risk method and the high-risk methods described above is striking. The European data show that where use of highrisk methods is common, use of sterilization is rare (Table 7).

The sterilization rate for women aged $41-45$ is exceptionally high for Great Britain (54\%) and slightly less so for West Germany ( $36 \%$ ). In contrast, sterilization is extremely low, or non-existent, in Italy $(0 \%)$ and Spain (3\%), and relatively low for France $(12 \%)$, while use rates for high-risk methods in these countries were $84 \%, 52 \%$ and $36 \%$, respectively. Overall, in the five countries the figure for sterilization is $21 \%$. Sterilization is illegal in Italy. The total hysterectomy rate in that country for women between 40 and 70 is $15.5 \%$, however, as compared to $11.4 \%$ for the total sample of six European countries studied by van Keep et al. (1983).

In the United States, sterilization is by far the most commonly chosen method among women aged 40 and over, in the form of tubal ligation or partner's vasectomy, with about $40 \%$ of all women aged $40-44$ being protected by contraceptive sterilization of either themselves $(25 \%)$ or their partners $(15 \%)$ (NSFG special run; Forrest \& Henshaw, 1983). Table 9 does not show when these sterilizations were performed, but about 45,500 American women aged 40-44 had tubal ligations in 1982 ( $7 \%$ of 650,000 tubal ligations: Grubb et al., 1985 ).

Sterilization is the most reliable method of contraception, and carries only slight surgical risk (primarily in the form of anaesthetic accidents), greater among older than among younger women, but with an overall risk of death about the same as with the IUD or abortion alone (Potts, 1979). Thus sterilization seems to be the ideal method for women who do not wish to have any more children, and appreciation of this fact 
can be seen in the use figures for the United States, Great Britain and the Federal Republic of Germany. Older women are on the whole less likely than younger women to regret having been sterilized (Liskin \& Rinehart, 1985). However, in view of present trends in childbirth at older maternal ages, particularly in the context of second marriages or unions, women may be more reluctant in future to opt for sterilization.

\section{Reversible methods}

Only $25 \%$ of American women aged $40-44$ (or their partners) use a reversible method of contraception: condom or diaphragm (barrier methods), the pill or the IUD. In the five European Countries, $32 \%$ of the women surveyed use reversible methods, more than the $21 \%$ who have opted for sterilization. Reversible methods are still much more widely used than in the US, not only in countries with high sterilization rates, such as Great Britain (33\% reversible methods) and West Germany $(39 \%)$, but also in those with low sterilization rates, such as Spain $(45 \%$ reversible methods) and France (42\%); the only exception is Italy, which shows a zero sterilization rate and a barrier method use rate of $16 \%$, as compared to a use rate of $84 \%$ for high-risk methods.

Barrier methods. Among American women surveyed, the most popular method was the condom, used by $30-40 \%$ of those in the $40-44$ age group using reversible methods. Over $40 \%$ of the older women in the age group under discussion use this method.

Condoms are liable to be regarded as unsatisfactory because, for example, they are 'less than aesthetic and often inconvenient' (Greenblatt, Nezhat \& McNamara, 1979). They are rarely mentioned as appropriate contraception for older women and are 'seldom prescribed and used today' (Stone, 1976). Moreover, the method suffers from being perceived as unreliable (Table 10). Among European women surveyed in the $41-45$ age group, only $15 \%$ used barrier methods, and $48 \%$ of this group stated that the reliability of the condom was doubtful; a further $13 \%$ found it frankly unreliable and $15 \%$ had no idea on the subject. The method was seen as reliable by only $24 \%$ of respondents, and by still fewer among the general group of women of all ages surveyed.

Nevertheless, there are advantages to the condom: it poses no health risk, it is available without prescription, and it protects against various infections. Furthermore, what are seen as disadvantages for younger women may constitute advantages for the older woman. Thus, the method is coitus-dependent, which means that while continuous protection is not provided, neither is continuous risk or cost. And what may be an unacceptably high failure rate among younger women is much lower among older women, who exhibit more consistent use of the method and lower fecundity. One possible disadvantage is that condom use may exacerbate problems of male impotence or ejaculatory difficulty which increase with age (Beard, 1979; Bowen-Simpkin, 1984).

Among American women using reversible methods, the diaphragm was considerably less popular than the condom, with a use rate of $9-13 \%$ in the $40-44$ age group. Vaginal laxity or cervical deformities resulting from childbirth may reduce the efficiency of the diaphragm for older women (Beard, 1979; Bowen-Simpkin, 1984). 
Table 10. Perceptions of reliability and safety in terms of health of contraceptive methods (\%), by women in five West European countries

\begin{tabular}{|c|c|c|c|c|c|c|c|c|}
\hline & \multicolumn{4}{|c|}{ Reliability } & \multicolumn{4}{|c|}{ Safety } \\
\hline & Reliable & Doubt & Unreliable & No idea & Safe & Doubt & Unsafe & No idea \\
\hline \multicolumn{9}{|l|}{ Pill } \\
\hline 15-19 & 42 & 45 & 2 & 11 & 9 & 66 & 12 & 13 \\
\hline All ages & 53 & 34 & 4 & 9 & 8 & 65 & 18 & 9 \\
\hline $41-45$ & 47 & 33 & 3 & 16 & 5 & 59 & 23 & 13 \\
\hline \multicolumn{9}{|l|}{ IUD } \\
\hline 15-19 & 32 & 40 & 4 & 24 & 12 & 41 & 19 & 28 \\
\hline All ages & 32 & 45 & 7 & 16 & 18 & 44 & 17 & 21 \\
\hline $41-45$ & 26 & 44 & 9 & 21 & 20 & 37 & 19 & 24 \\
\hline \multicolumn{9}{|l|}{ Condom } \\
\hline $15-19$ & 14 & 60 & 12 & 14 & 27 & 26 & 14 & 33 \\
\hline All ages & 20 & 55 & 12 & 13 & 38 & 21 & 12 & 29 \\
\hline $41-45$ & 24 & 48 & 13 & 15 & 41 & 19 & 13 & 27 \\
\hline
\end{tabular}

Source: Riphagen et al. (1985, 1986).

IUD. The three American surveys used differ somewhat in their estimates of the proportion of US women aged 40-44 who use IUDs (Table 8). Among California Medicaid patients (certainly not typical), the IUD is the most popular reversible method, used by $40 \%$ of clinic clients. In the two national surveys, the NSFG shows a $19 \%$ use rate, the Market Survey only $12 \%$.

Among European women surveyed, the mean use rate (Table 7) was a mere $11 \%$. The highest rate per country was among French respondents $(23 \%)$ with a rate of $14 \%$ for Spain, and very low rates of $4 \%, 7 \%$, and $7 \%$ for Italy, Great Britain and West Germany, respectively.

There is disagreement as to the appropriateness of intrauterine contraception for older women. There are two major disadvantages to the IUD. The first is increased risk of pelvic inflammatory disease and the subsequent possibility of infertility. Assuming that older women are less at risk for contracting sexually transmitted diseases and, therefore, pelvic inflammatory disease and have probably completed their childbearing, this disadvantage becomes relatively unimportant.

The second disadvantage is bleeding and cramping, which may be exacerbated if fibroids are present or if there is perimenopausal menorrhagia. But if patients are adequately screened and have no initial bleeding problems, additional problems are not to be anticipated, although there are no data to demonstrate this. An exception might be insertion problems in women who have had previous cervical surgery (Beard, 1979).

In the five-country survey there was a disturbingly high percentage of respondents with misconceptions about the safety and efficacy of the IUD. In women in the 41-45 age group, $44 \%$ expressed doubts about its reliability, $37 \%$ doubts about its safety in health terms, while a further $19 \%$ described the method as definitely unsafe (Table 10). 
Table 11. Percentage of all women aged 40-54 who currently take oral contraceptives

\begin{tabular}{|c|c|c|c|c|}
\hline \multirow[b]{2}{*}{ Age } & \multicolumn{2}{|c|}{$\begin{array}{c}\text { HANES II* } \\
1976-80\end{array}$} & \multicolumn{2}{|c|}{$\begin{array}{c}\text { Nurse study } \dagger \\
1976\end{array}$} \\
\hline & $\%$ & $N$ & $\%$ & $N$ \\
\hline $40-44$ & $4 \cdot 4(1 \cdot 3)$ & 282 & 6.4 & 1085 \\
\hline $45-49$ & $6 \cdot 2(2 \cdot 2)$ & 201 & $5 \cdot 1$ & 640 \\
\hline $50-54$ & $2.5(1.8)$ & 79 & 3.8 & 188 \\
\hline
\end{tabular}

Sources: * Russel-Briefel et al. (1985); † Lipnick et al. (1986).

However, the IUD is an excellent method of contraception for older women. It is effective and convenient, and IUD-related problems are far less likely to occur, and to be of less consequence, in older than in younger women.

Oral contraception. There is probably more controversy about pill use among older women than about any other method. This concerns both how many older women use the pill and whether or not they should use it. One complicating factor is that new developments in oral contraceptives resulting in safer pills may have passed by older age groups.

In the National Survey of Family Growth, only 3\% of American women aged 40-44 using reversible contraception used the pill (Table 8); this was the least popular method of contraception (Pratt et al., 1984). In the Market Survey, 16\% of women used the pill and it was third in popularity among reversible methods for older women (Forrest \& Henshaw, 1983).

The Health and Nutrition Examination Survey (HANES) Cycle II (Table 11) found that $4 \cdot 4 \%$ of all women aged $40-44$ (i.e. not merely those using reversible contraception) were taking oral contraceptives (Russel-Briefel, Ezzati \& Perlman, 1985). And a survey of 121,964 nurses aged $30-55$, based on a mailed questionnaire, found that $6.4 \%$ of US nurses aged $40-44$ were currently taking the pill (Lipnick et al., 1986). These two studies also provide information on women aged 45 and older. The HANES II study suggests that about 403,000 women over 40 , and 29,000 over 50 , are using the pill.

Perceptions of the pill tended to be extremely negative. A Gallup poll carried out in January 1985 on behalf of the American College of Obstetrics and Gynecology found that $76 \%$ of American women saw substantial risks in using the pill, $31 \%$ thought it caused cancer, and $64 \%$ (incorrectly) saw childbearing as a risk smaller than or equal to taking the pill-opinions 'markedly inconsistent with the scientific evidence' (Report of the Perceptions of the Pill Survey Group, 1987).

European figures for pill use were low (Table 7), only 6\% for women aged 41-45. Of the individual countries, only the Federal Republic of Germany had a sizable use rate $(19 \%)$. Rates in the remaining four countries are modest: $10 \%$ in France, $8 \%$ in Spain, $3 \%$ in Great Britain and $0 \%$ in Italy.

Discrepancies between data relating to perceptions of reliability and of health 
safety are even more striking for the pill than for the IUD. Of the women questioned, $47 \%$ considered the pill reliable; $5 \%$ considered it safe. Three per cent of those surveyed considered the pill to be unreliable; $23 \%$ said it was unsafe, and a sizable percentage $(33 \%)$ had doubts about pill safety. These perceptions are not limited to the age group under discussion; there appears (Table 10) to be very little variation with age.

Among gynaecologists, some believe that use of oral contraception is justified in older women, provided that they are in good health and medically supervised (Bowen-Simpkin, 1984; Connell, 1984; Friedman, 1974). Others, perhaps a majority, would give qualified approval (Stone, 1976; Weisberg, 1985), and some feel that pill use is almost never justified.

The controversy surrounding the advisability of oral contraceptive use by older women reflects the incomplete understanding of the effects of pre- and postmenopausal oestrogens and progestins; this is especially true of the newer formulations. Women using contraceptive oestrogens have an increased risk of cardiovascular disease morbidity and mortality. While postmenopausal oestrogens reduce the risk of cardiovascular disease (Bush \& Barrett-Connor, 1985), three large cohort studies and many case-control studies have established beyond doubt that the risk of myocardial infarction and stroke among women using the older oral contraceptive formulations increases with age. Data are still lacking on the new formulations.

In women over 40 , the relative risk of myocardial infarction is four times greater among pill users, and the relative risk of stroke is five times greater (Stadel, 1981). Among non-smokers, however, the absolute risk remains quite small, even in this age group, while the risk of maternal mortality and morbidity increases rapidly with age. While the great majority of oral contraceptive deaths occur in women who smoke or who are over 35 , the normotensive, slim non-smoker can probably safely use oral contraception if she is medically supervised. Furthermore, oral contraception provides excellent cycle control and hormone replacement therapy at a time when both of these are desirable (Bowen-Simpkin, 1984). Oral contraception may also relieve undesirable symptoms of the menopause (Kase, 1976; Shargil, 1985).

There is some confusion about the role played by the progestin component (Meade, Greenberg \& Thompson, 1980). Injectable long-acting progestogens have the advantage that they seem to have few metabolic side effects. But the disruption of bleeding patterns may, in this age group, require a diagnostic curettage.

Older women are more likely than younger women to be taking oral contraceptives containing relatively high oestrogen doses (Table 12). In a study of Medicaid claims for prescriptions in Minnesota and Michigan in 1980, van de Carr et al. (1983) report that $25-26 \%$ of Michigan women aged 35-49 were filing prescriptions for pills containing $60+\mu \mathrm{g}$ of oestrogen, compared with only $16 \%$ of the total of oral contraceptive prescriptions. In Minnesota, the results were even more striking: $39 \%$ of women aged $45-49$ were using the highest dose oestrogen pills $(24 \%$ of those aged $35-39,14 \%$ of those aged $40-44$ ), compared with $14 \%$ of all women. The authors suggest three reasons: (1) brand loyalty - that is, older women started pill use earlier and continue with the same brand, to their obvious disadvantage; (2) physicians concentrate on starting new users on low dose brands because of the 
Table 12. Percentage of women using highest dose (60-150 $\mu \mathrm{g}$ oestrogen) oral contraceptives, by age: Medicaid patients, $1980(N=81,968)$

\begin{tabular}{lcc}
\hline & Michigan & Minnesota \\
\hline $40-44$ & 26 & 14 \\
$45-49$ & 25 & 39 \\
All ages & 16 & 14 \\
$\%$ of all users aged $40+$ & $1 \cdot 1$ & $1 \cdot 4$ \\
\hline
\end{tabular}

Source: van de Carr et al. (1983).

greater duration of future exposure; and (3) older women are more concerned about pregnancy and therefore prefer the higher doses.

The authors considered the last reason to be the least likely, but the reasons are clearly not thoroughly understood, and more research is called for.

\section{Conclusions}

In all the countries studied, reliability was an important factor in choice of contraceptive method. In the US 20-25\% of all the women studied chose sterilization as a method of contraception. American couples are more likely to choose sterilization than all other methods combined. Sterilization rates in Europe varied.

Generally, the older woman has a greater array of contraceptive methods available to her, because her lower fecundity tends towards lower failure rate than among younger women, and because of a reduced concern for future fertility. Reduced fecundity may make barrier methods more acceptable to this age group, although fear of pregnancy may be greater among older than among younger women. Widespread use of condoms by this group suggests that consistent use coupled with lower fecundity leads to acceptable failure rates.

Perceptions of safety proved to be even more important than perceptions of reliability, however, in choosing a method of contraception. Both the pill and the IUD, in particular, suffered from women's perceptions of them as either unsafe or possibly hazardous to health.

In general, there is very little information available about contraceptive practices among women over 40 , despite the fact that such information is essential if the contraceptive needs of this age group, which has in the past two decades undergone a transition in attitudes and behaviour in many Western countries, are to be met adequately.

It is also possible that contraceptives developed for the general population are more effective than need be for older women, resulting in 'contraceptive overkill' (Jansen, 1984). There is a need for carefully designed clinical trials of the use of certain methods, such as the new hormonal formulae, by older women, especially as they approach the menopause.

Women between the ages of $\mathbf{4 0}$ and 50 may be less fecund than younger women, but they do not make sufficient use of contraception. Non-use of contraception 
obviously varies with several factors, including nationality, religion, age, education, employment, marital status, and number of children. In general, however, perceptions among this age group of the reliability of contraceptive methods are similar and quite realistic. Similarly, perceptions of negative health effects cut across groups; these perceptions, however, tend to be unrealistic.

The negative effects of certain methods such as oral contraceptives and IUDs are overestimated by all age groups and in all countries studied. This suggests a general state of misinformation that could have a major effect on choice of contraceptive method, since health considerations are the prime motive for choosing or abandoning a specific method. This becomes particularly important because the women in this age group do not necessarily exclude a future, planned pregnancy. In view of indications that many Western countries, including the United States, are currently seeing a trend towards delayed childbearing (Francis, 1985), the use of reversible contraception must be considered too low.

The controversy surrounding pill use in older women is not likely to be resolved in the near future, however. Women who have done well on oral contraceptives in the past will probably continue to do so as they approach the menopause (Taubert, 1985). Women who have not done well on them will not wish to adopt this method later in life, particularly in view of the prevalent negative view of pill safety.

A further problem, particularly in the United States, is that a woman who wishes to take the pill may have to change doctors in order to do so. Physicians' reluctance to prescribe the pill for older women may well increase as medical litigation increases.

The problem of diminishing availability in the United States is also a critical one for IUDs, almost all of which have been withdrawn from the market by manufacturers who see no commercial value for their product in a highly litigious climate (Forrest, 1986). There is likely to be a three-fold increase in the risk of unwanted pregnancies among those women unable to continue IUD use (Forrest, 1986). There is already some evidence that those women in the United States who can afford to do so are crossing the border into Canada to obtain IUDs or are seeking them in Europe. Some women who are due to have their IUDs replaced will elect to keep them in place, which may cause problems. Research is needed to show whether the IUD's effectiveness declines more or less quickly than its wearer's fecundity after age 40 .

Sterilization is a readily available, risk-free method of contraception for those women who have decided that they do not want (further) children. However, women increasingly willing to consider the idea of later pregnancies should have a better understanding of the risk of natural methods and of the nature of the health risks associated with reversible methods. Women and their physicians should be made aware of improvements in IUD design and of the lowering of hormone levels in oral contraceptives so that they can make contraceptive choices on the basis of realistic factors rather than unfounded fears.

Moreover, the implications of widespread misinformation go beyond the women surveyed. The under-utilization of contraception and the lack of knowledge concerning contraceptive methods not only pose a risk to the women involved but present an on-going hazard: women in the age group under discussion frequently have teenage children, and several studies have shown that teenagers depend heavily 
on family members or friends for advice about contraception (Riphagen et al., 1984, 1985a,b, 1986a,b).

\section{Acknowledgment}

Support for the American study was provided by Family Health International, with funds from the US Agency for International Development.

\section{References}

Aved, B. (1985) Patterns of contraceptive method use by California family planning clinic clients, 1976-1984. Am. J. publ. Hlth, 75, 1210.

BEARD, R. J. (1979) Diseases affecting contraceptive practice in middle age. J. biosoc. Sci. Suppl. 6, 143.

BongaArts, J. (1982). Infertility after age 30: a false alarm. Fam. Plann. Perspectives, 14, 75.

Bowen-Simpkin, P. (1984) Contraception for the older woman. Br. J. Obstet. Gynec. $91,513$.

BUSH, T. \& BARRETT-CONNOR, E. (1985) Noncontraceptive estrogen use and cardiovascular disease. Epidemiol. Rev. 80.

Centers for Disease Control, Cancer and Steroid Hormone Study (1983) Long-term oral contraceptive use and the risk of breast cancer. J. Am. med. Ass. 249, 1591.

CONNELL, E. B. (1984) Contraceptive needs of the middle-aged couple. Contemporary Obstet. Gynec. $24,94$.

ForReST, J. D. (1986) The end of marketing of IUDs in the United States: what does it mean for American women? Fam. Plann. Perspect. 18, 2.

ForRest, J. D. \& HeNSHAw, S. (1983) What US women think and do about contraception. Fam. Plann. Perspect. 15, 157.

FranCIS, H. H. (1985) Delayed childbearing. IPPF Med Bull. 19, 3.

Friedman, S. (1974) What contraceptive measures for women in their 40 s and 50s? J. Am. med. Ass. 230, 759.

GRAY, R. H. (1979) Biological and social interactions in the determination of late fertility. J. biosoc. Sci. Suppl. 6, 97.

Greenblatt, R. B., Nezhat, C. \& McNamara, V.P. (1979) Appropriate contraception for middleaged women. J. biosoc. Sci. Suppl. 6, 119.

Grubb, G. S., Peterson, H. B., Layde, P. M. \& Rubin, G. L. (1985) Regret after decision to have a tubal sterilization. Fert. Steril. 44, 248.

Howe, H. L. (1984) Age-specific hysterectomy and oophorectomy prevalence rates and the risks for cancer of the reproductive system. Am. J. publ. Hlth, 74, 560 .

Instituto Nacional Estadistica (1986) Encuesta de Fecundidad 1985, Avance de Resultados. Madrid.

JANSEN, R. P. S. (1984) Fertility in older women. IPPF Med. Bull. 18, 6.

KASE, N. G. (1976) The sexually active premenopausal woman. (Chez, R. A., Moderator). Dialogues in Oral Contraception, $\mathbf{1 .}$

Lipnick, R. J., Buring, J. E., Hennekens, C. H., Rosner, B., Willett, W., Bain, C., Stampfer, M. J., Colditz, G. A., PEto, R. \& SPeizer, F. E. (1986) Oral contraceptives and breast cancer. J. Am. med. Ass. 255, 58.

LISKIN, L. \& RineHART, W. (1985) Minilaparotomy and Laparoscopy: Safe, Effective and Widely Used. Population Reports Series C, No. 9. Johns Hopkins University, Baltimore.

MEAdE, T. W., GreenBerg, G. \& ThOmpson, S. G. (1980) Progestagens and cardiovascular reactions associated with oral contraceptives and a comparison of 50 - and $30-\mu \mathrm{g}$ oestrogen preparations. Br. med. J. 286, 1157. 
National Center for Health Statistics (1984a) Vital Statistics of the United States, 1979, Vol. 1, Natality. DHSS Publication No. (PHS) 84 1101, USPHS, Washington, DC.

National Center for Health Statistics (1984b) Vital Statistics of the United States, 1979, Vol. 2, Mortality, Part A. DHSS Publication No. (PHS) 84 1101. USPHS, Washington, DC.

Nolan, T. F., ORY, H. W., Hughes, J. M. \& Greenspan, J. R. (1982) Cumulative prevalence rates and corrected incidence rates of surgical sterilization among women in the United States, 1971-1978. Am. J. Epidemiol. 116, 776.

Office of Population Censuses and Surveys (1985) General Household Survey 1983. HM Stationery Office, London.

Potrs, M. (1979) Discussion on sterilization and abortion in middle age. J. biosoc. Sci. Suppl. 6, 157.

Pratt, W. F., Mosher, W. D., BaChrach, C. A. \& Horn, M. C. (1984) Understanding U.S. fertility: findings from the National Survey of Family Growth, Cycle III. Popul. Bull. 39, No. 5, Table 7.

Report of The Perceptions of The Pill Survey Group (1987) Women's perceptions of the safety of the pill: a survey in eight developing countries. J. biosoc. Sci. 19, 313.

RiPHAGEN, F. E., VAN DER VURST, J. \& LeHERT, P. (1984) Contraception in Italy. International Health Foundation, Geneva.

Riphagen, F. E., VAN Der Vurst, J. \& LeherT, P. (1985a) Contraception in France. International Health Foundation, Geneva.

Riphagen, F. E., VAn Der Vurst, J. \& Lehert, P. (1985b) Contraception in Great Britain. International Health Foundation, Geneva.

Riphagen, F. E., VAn Der Vurst, J. \& Lehert, P. (1986a) Contraception in Spain. International Health Foundation, Geneva.

Riphagen, F. E., VAN Der VURSt, J. \& Lehert, P. (1986b) Contraception in the Federal Republic of Germany. International Health Foundation, Geneva.

Russel-Briefel, R., Ezzati, T. \& Perlman, J. (1985). Prevalence and trends in oral contraceptive use in premenopausal females aged 12-54 years, United States, 1971-1980. Am. J. publ. Hlth, 75, 1173.

SHARGIL, A. A. (1985) Hormone replacement therapy in perimenopausal women with a triphasic contraceptive compound: a three-year prospective study. Int. J. Fertil. 30, 15.

StAdEl, B. V. (1981) Oral contraceptives and cardiovascular disease. Parts I and II. New Engl. J. Med. 305, 612, 672.

Stone, S. C. (1976) Discontinuing contraception at menopause. Med. Asp. hum. Sexuality, May, p. 177.

Taubert, H. D. (1985). In: The Climacteric Perspective. Edited by M. Notelovitz \& P. van Keep. MTP, Lancaster.

van de Carr, S. W., Kennedy, D. L., Rosa, F. W., Anello, C. \& Jones, J. K. (1983) Relationship of oral contraceptive estrogen dose to age. Am. J. Epidemiol. 117, 153.

VAN KeEP, P., WildermeERSCH, D. \& LeHERT, P. (1983) Hysterectomy in six European countries. Maturitas, 5, 69.

Ventura, S. J. (1982) Trends in First Births to Older Mothers, 1970-1979. Monthly Vital Statistics Report, 31(2), Supplement (2). National Center for Health Statistics, Washington, DC.

WALKER, A. M. \& JiCK, H. (1979) Temporal and regional variation in hysterectomy rates in the United States, 1970-1975. Am. J. Epidemiol. 110, 41.

WeISBERG, E. (1985) Contraception for the older woman: a review. Clin. Reprod. Fert. $20,115$.

WORLD Fer TILITY SUR VeY. Summary of Findings No. 32 (1981). The Hague.

World Fertility Survey. Comparative Studies No. 20 (1982). The Hague.

World Health Organization (1981) Research on the Menopause. Fertility Regulating Methods for Women Approaching the Menopause, Chap. 9, Technical Report Series 670, WHO, Geneva. 